\section{What is already known on this topic}

It has been extremely difficult to investigate anatomical changes during the act of coitus and the female sexual response

Modern magnetic resonance imaging allows exploration of aspects of living anatomy

\section{What this paper adds}

Taking MR images of the male and female genitals during coitus is feasible

During 'missionary position' intercourse the penis has the shape of a boomerang

During female sexual arousal without intercourse the uterus rises and the anterior vaginal wall lengthens

The size of the uterus does not increase during sexual arousal

the typescript; and Professor W Mali for offering the use of equipment at the University Hospital Utrecht. P van Andel does not want to be acknowledged for his idea of using MRI to study coitus. He excuses himself by quoting the French romantic poet Alphonse de Lamartine (1790-1869): "C'est singulier! Moi, je pense jamais, mes idées pensent pour moi."

Contributors: WWS initiated and coordinated the formulation of the study hypothesis, designed the protocol, and participated in data collection, interpretation of the findings, and writing of the paper; he is guarantor of the study. PvA had the original idea for the present study, and participated in formulation of the study hypothesis, data collection, interpretation of the findings, and writing of the paper. IS, together with her partner, participated in the first two experiments and helped design the protocol. EM participated in the execution of the study, particularly data collection and interpretation of the magnetic resonance findings.

Funding: No additional funding.

Competing interests: None declared.

1 Chianchi M. Leonardo, the anatomy. Florence: Giunti, 1998:56.

2 Clark K, Pedretti C. The drawings of Leonardo da Vinci in the collection of Her Majesty the Queen at Windsor Castle. London: Phaidon, 1968.

3 Dickinson RL. Human sex anatomy, a topographical hand atlas. 2nd ed. London: Baillière, Tindall and Cox, 1949:84-109.

4 Masters WH, Johnson VE. Human sexual response. Boston: Little, Brown, 1966.

5 Johnson VE, Masters WH, Lewis KC. The physiology of intravaginal contraception failure. In: Calderone MS, ed. Manual of contraceptive practice. Baltimore: Williams and Wilkins, 1964:138-50.

6 Riley AJ, Lees W, Riley EJ. An ultrasound study of human coitus. In: Bezemer W, Cohen-Kettenis P, Slob K, Van Son-Schoones N, eds. Sex matters. Amsterdam: Elsevier, 1992:29-36

7 Sohn MH, Wein B, Bohndorf K, Handt S, Jakse GIJ. Dynamic magnetic resonance imaging (MRI) with paramagnetic contrastagens: a new concept for evaluation of erectile impotence. Impotence Res 1991:3:36-48.

8 Levin RJ. Sex and the human female reproductive tract-what really happens during and after coitus. Int J Impotence Res 1998;10(suppl 1):14-21.

9 Van Andel P. Anatomy of the unsought finding. Serendipity: origin, history, domains, traditions, appearances and programmability. Br J Phil Sci 1994;45:631-48.

10 O'Connell HE, Hutson JM, Anderson CR, Plenter RJ. Anatomical relationship between urethra and clitoris. J Urol 1998;159:1892-7.

11 Krantz KE. Innervation of the human vulva and vagina. Obstet Gynecol 1985; 12:382-96.

12 Minh MH, Smadja A, De Sigalony JPH, Aetherr JF. Role du fascia de Halban dans la physiologie orgasmique feminime. Cahiers de Sexuol Clin 1981;7:169

13 Hilleges M, Falconer C, Ekman-Ordeberg G, Johanson O. Innervation of the human vaginal mucosa as revealed by PGP 9.5 immunohistochemistry. Acta Anatomica 1995:153:119.

14 Alzate H, Londono ML. Vaginal erotic sensitivity. I Sex Marital Ther 1984;10:49-56.

15 Hoch Z. Vaginal erotic sensitivity by sexual examination. Acta Obstet Scand 1986;5:767-73.

16 Weijmar Schultz WCM, Van de Wiel, HBM, Klatter JA, Sturm BE, Nauta J Vaginal sensitivity to electric stimuli, theoretical and practical implications. Arch Sex Behav 1989;18:87-95.

17 Fleck L. Genesis and development of a scientific fact. Chicago: University of Chicago Press, 1979:35. (Translation of Entstehung und Entwicklung einer Wissenschaftliche Tatsache:Einführung in die Lehre vom Denkstil und Denkcollectiv. Basel: Benno Schwabe, 1935.)

\title{
Shaken, not stirred: bioanalytical study of the antioxidant activities of martinis
}

\author{
C C Trevithick, M M Chartrand, J Wahlman, F Rahman, M Hirst, J R Trevithick
}

Department of

Biochemistry,

Faculty of Medicine

and Dentistry,

University of

Western Ontario,

London, Ontario,

Canada N6A 5C1

C C Trevithick

research assistant

M M Chartrand

research assistant

J Wahlman

research assistant

F Rahman

research assistant

M Hirst

professor

J R Trevithick

professor

Correspondence to: J R Trevithick trevjohn@julian.

uwo.ca

BMJ 1999;319:1600-2

\section{Abstract}

Background Moderate consumption of alcoholic drinks seems to reduce the risks of developing cardiovascular disease, stroke, and cataracts, perhaps through antioxidant actions of their alcohol, flavonoid, or polyphenol contents. "Shaken, not stirred" routinely identifies the way the famous secret agent James Bond requires his martinis.

Objectives As Mr Bond is not afflicted by cataracts or cardiovascular disease, an investigation was conducted to determine whether the mode of preparing martinis has an influence on their antioxidant capacity.

Design Stirred and shaken martinis were assayed for their ability to quench luminescence by a luminescent procedure in which hydrogen peroxide reacts with luminol bound to albumin. Student's $t$ test was used for statistical analysis.

Results Shaken martinis were more effective in deactivating hydrogen peroxide than the stirred variety, and both were more effective than gin or vermouth alone $(0.072 \%$ of peroxide control for shaken martini, $0.157 \%$ for stirred $v 58.3 \%$ for gin and $1.90 \%$ for vermouth). The reason for this is not clear, but it may well not involve the facile oxidation of reactive martini components: control martinis through which either oxygen or nitrogen was bubbled did not differ in their ability to deactivate hydrogen peroxide $(0.061 \% v 0.057 \%)$ and did not differ from the shaken martini. Moreover, preliminary experiments indicate that martinis are less well endowed with polyphenols than Sauvignon white wine or Scotch whisky $(0.056 \mathrm{mmol} / \mathrm{l}$ (catechin equivalents) shaken, $0.060 \mathrm{mmol} / 1$ stirred $v 0.592$ $\mathrm{mmol} / \mathrm{l}$ wine, $0.575 \mathrm{mmol} / \mathrm{l}$ whisky).

Conclusions 007's profound state of health may be due, at least in part, to compliant bartenders.

\section{Introduction}

James Bond, the well known fictional secret agent ("007") of the British intelligence services, not only is 


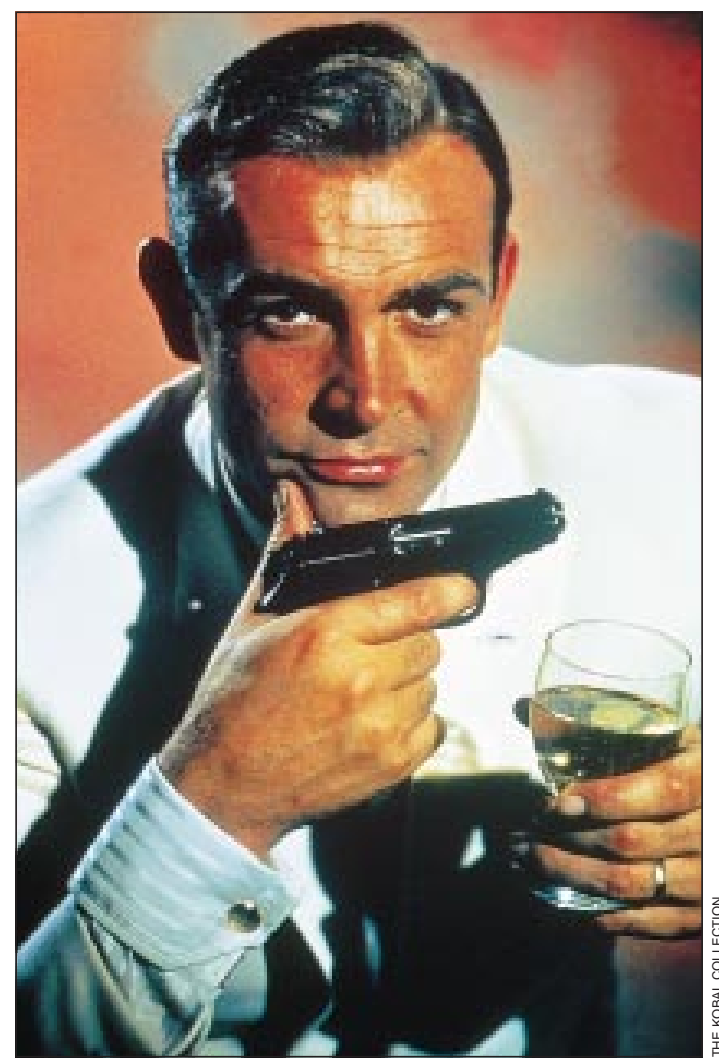

Is it martinis that help James Bond stay so healthy?

astute in matters of clandestine affairs at a personal and international level but may also possess insights of interest to medical science. Take for example his insistence on having his martini "shaken, not stirred." Does this straightforward direction to the barman merely yield a crisper drink, more to James Bond's taste, or is there more to it?

Moderate consumption of alcoholic beverages has been associated with a decreased risk of several age related diseases, including cardiovascular disease, ${ }^{12}$ stroke, ${ }^{3}$ and cataract. ${ }^{45}$ This effect has been tentatively ascribed to the antioxidant activities of alcohol, ${ }^{6}$ flavonoids, or polyphenols ${ }^{7}$ in the beverages, since it has been established that the antioxidant vitamin $\mathrm{E}$ reduces the risk of cardiovascular disease $^{89}$ and cataract development. ${ }^{10}$

\section{Methods}

Mini-martinis were prepared by mixing two parts (vol/vol) gin $(6 \mathrm{ml})$ with one part vermouth $(3 \mathrm{ml})$. They were either shaken vigorously $(9 \mathrm{ml}$ in a $100 \mathrm{ml}$ medicine bottle for one minute), or stirred (9 $\mathrm{ml}$ in a $20 \mathrm{ml}$ glass vial, using a vortex mixer). Aliquots of the martinis were then added into a luminescent assay ${ }^{11} 12$ to see if they altered the luminescence resulting from the addition of a standard amount of hydrogen peroxide. In both cases, the addition of the martinis decreased the net luminescence to a small percentage of control values. When we analysed the net luminescence statistically, using the $t$ test function of Microsoft's Excel spreadsheet program, the luminescence remaining after we added the shaken mixture to the peroxide was virtually half that afforded by the stirred mixture (table $1, \mathrm{P}=0.0057$ ). This indicates that there was twice as much peroxide remaining after treatment with the stirred martinis than after the shaken variety. Thus, shaken martinis are better able to "neutralise" peroxide than stirred martinis.

The normalised luminescent count rate is reduced by the addition of martinis. Counts per minute were obtained with a Lumac Biocounter M2010 (Celsis, Chicago) when hydrogen peroxide was incubated with the luminol bound to albumin, as described below. Samples consisted of an aqueous portion $(0.3 \mathrm{ml})$, and a dimethyl sulphoxide portion $(0.4 \mathrm{ml})$. The aqueous portion contained luminol and albumin $\left(0.02 \mathrm{ml}, 10 \mathrm{mg} / \mathrm{ml}\right.$ of each) prepared as described, ${ }^{11} 12$ and phosphate buffered saline $(0.11 \mathrm{ml})$ containing martini $(0.07 \mathrm{ml})$ or distilled water (for control). Hydrogen peroxide $(0.1 \mathrm{ml}$ of $1.0 \%$, final concentration 42 $\mathrm{mmol} / \mathrm{l}$ ) was added after the addition of dimethyl sulphoxide $(0.4 \mathrm{ml})$, just before the tube was placed in the counter to begin counting of the emitted light. We determined the probability that the means of each set of samples are identical by using Student's $t$ test in the Excel program.

We considered that a difference might arise from air oxidation of reactive martini components during the vigorous shaking. This may, however, not be the reason because when, as an alternative to shaking or stirring, we vigorously bubbled air or nitrogen at similar rates through the martinis (for one minute), the two treatments showed no significant difference in net luminescence (table 1). Nevertheless, the martinis bubbled with both air and nitrogen showed net luminescent counts equivalent to the shaken rather than to the stirred martinis.

\section{Results}

To ascertain the relative contribution of the gin and vermouth components, both were assayed in a preliminary experiment for their abilities to reduce luminescence produced by the peroxide challenge. Vermouth was much more potent, causing a 98.1\% (SE 0.5\%) $(n=3)$ decrease in count rate, while gin reduced the count rate after challenge with peroxide by only $41.7 \%$ $(14.1 \%) \quad(n=36)$. This implies that the vermouth contributes more to the antioxidant properties of martinis. Even so, the combination of gin and vermouth is

Table 1 Remaining luminescence after addition of martinis to the luminescent assay containing peroxide

\begin{tabular}{|c|c|c|c|c|c|}
\hline \multirow[b]{2}{*}{ Manoeuvre } & \multirow[b]{2}{*}{ No of samples } & \multicolumn{3}{|c|}{ Percentage of peroxide control value } & \multirow[b]{2}{*}{ Significance (shaken $v$ stirred) } \\
\hline & & Mean & SE & $95 \% \mathrm{Cl}$ & \\
\hline Shaken & 7 & 0.072 & 0.020 & 0.023 to 0.121 & \multirow{2}{*}{$t=3.418(d f=11) P=0.0057$} \\
\hline Stirred & 6 & 0.157 & 0.016 & 0.113 to 0.201 & \\
\hline Air bubbled through mix & 5 & 0.061 & 0.007 & 0.044 to 0.077 & \multirow{2}{*}{$t=0.126(d f=8) P=0.904$} \\
\hline Nitrogen bubbled through mix & 5 & 0.057 & 0.030 & -0.027 to 0.140 & \\
\hline
\end{tabular}


Table 2 Polyphenol content of martinis compared with white wine and blended Scotch whisky

\begin{tabular}{lcccc}
\multirow{2}{*}{$\begin{array}{c}\text { No of } \\
\text { Sample }\end{array}$} & \multicolumn{3}{c}{ Catechin equivalent concentration (mmol/l) } \\
\cline { 2 - 5 } & 8 & Mean & SE & 95\% Cl \\
\hline Shaken martini & 9 & 0.056 & 0.005 & 0.044 to 0.068 \\
\hline Stirred martini & 0.060 & 0.009 & 0.039 to 0.081 \\
\hline Sauvignon white wine & 9 & 0.592 & 0.030 & 0.523 to 0.661 \\
\hline Scotch whisky & 9 & 0.575 & 0.025 & 0.517 to 0.633 \\
\hline
\end{tabular}

Assay performed by adding $20 \mu \mathrm{l}$ sample to $980 \mu \mathrm{l}$ Folin reagent diluted $1 / 10$ with distilled water; colour allowed to develop for $0.5-2.5$ hours the absorbance of the solution at $750 \mathrm{~nm}$ was read. Samples were compared with a standard curve prepared by adding $10-50 \mu \mathrm{l}$ of $1 \mathrm{mmol} / \mathrm{l}$ catechin solution to Folin reagent. Standard curves measured on three days had $R^{2}$ values of $0.9984-0.9999$.

better than either gin or vermouth alone, resulting in a much lower net luminescent count rate $(0.072 \%$ of peroxide control for the shaken martini) than those found after either gin $(58.3 \%$ of control) or vermouth (1.9\% of control) alone. The remaining luminescence with martinis is substantially lower than that of the vermouth itself.

Since much of the antioxidant activity of wine and whisky has been ascribed to the polyphenols they contain, ${ }^{7}$ the polyphenol content in the martinis was investigated using Folin reagent. ${ }^{7}$ As shown in table 2, the phenolic concentrations in the martinis, in catechin equivalents, were an order of magnitude lower than those in white wine or 12 year old Scotch whisky, and there was no significant difference between the phenolic contents of shaken and stirred martinis.

The martinis, when undiluted, are capable of suppressing counts from $42 \mathrm{mmol} / \mathrm{l}$ peroxide by over $99.9 \%$. We calculate that after ingestion an absorbed martini may be able to react with $210 \mu \mathrm{mol} / \mathrm{l}$ of hydrogen peroxide. We have previously determined that $5 \mathrm{mmol} / \mathrm{l}$ ethanol, a blood concentration of ethanol found after absorption of one or two typical alcoholic drinks, would eliminate $131 \mu \mathrm{mol} / \mathrm{l}$ peroxide. ${ }^{6}$ The peroxide concentrations detected in the aqueous humour have ranged from $14 \mu \mathrm{mol} / 1$ to $31 \mu \mathrm{mol} / \mathrm{l}$ : mean 24 (SE 7) $\mu \mathrm{mol} / \mathrm{l}$ for normal humans, with higher concentrations in cataract patients (82 (155) $\mu \mathrm{mol} / \mathrm{l}$ and $\left.198(88) \mu \mathrm{mol} / \mathrm{1}^{13}\right)$. Both vitamin $\mathrm{E}$ and ethanol decrease the risk of cataract ${ }^{45}$ and atherosclerosis ${ }^{13}$ by about half. The residual peroxide concentrations in the aqueous humour possibly reflect those in the serum, from which the aqueous humour is formed by ultrafiltration at the ciliary body. After the consumption of shaken martinis, peroxide concentrations of serum and aqueous humour could be half those found after ingestion of stirred martinis.

\section{Discussion}

Although the reason for the superior antioxidant activity of shaken martinis is not clear, is it possible that James Bond chose shaken (not stirred) martinis because of the improved antioxidant potential? This added antioxidant effect could result, of course, in a healthier beverage. There is no indication in the literature that 007 suffered from cataracts or cardiovascular disease, hence he must be considered a moderate consumer of alcoholic drinks. The authors have not examined any antioxidant contributions from olives.

Contributors: CCT originated the idea and performed preliminary experiments on the antioxidant activity of martinis. FR and MMC performed the Student's $t$ tests using the Excel spreadsheet program, and MMC performed the Folin pheno content determinations and statistical analysis. JW and FR, with assistance from Darin Lawrence, Adrian Lee, and Ashley MacDonald, prepared the mini-martinis and performed antioxidant assays using the luminometer. MH and JRT coordinated the study, aided in the statistical analysis, suggested appropriate tests and controls to perform in group meetings, and were mainly responsible for writing the paper. CCT and MMC suggested editorial changes to the text. JRT and $\mathrm{MH}$ are guarantors of the paper.

Funding: Except for MH and JRT, all staff on the project were summer students supported by Work Study, Canada Manpower, Youth Opportunities Unlimited Ontario, and by grants from Labatt Breweries to MH and JRT. Corby Distilleries provided samples of gin and vermouth.

Competing interests: The research grants from Labatt Breweries were used for a portion of the laboratory supplies, a portion of expenses incurred by CCT, MMC, JW, and JRT in attending the conference of the Association for Research in Vision and Ophthalmology (1999), and a portion of the expenses of $\mathrm{MH}$ in attending the fourth international conference on toxicology in developing countries (1999).

1 Klatsky AL. Epidemiology of coronary heart disease-influence of alcohol. Alcohol Clin Exp Res 1994;18:88-96.

2 Kiechl S, Willeit J, Egger G, Oberhollenzer M, Aichner F. Alcohol consumption and carotid atherosclerosis: evidence of dose-dependent atherogenic and antiatherogenic effects. Results from the Bruneck Study. Stroke 1994;25:1593-8.

3 Sacco RL, Elkind M, Boden-Albala B, Lin IF, Kargman DE, Hauser WA, et al. The protective effect of moderate alcohol consumption on ischemic stroke. JAMA1999;281:53-60.

4 Clayton RM, Cuthbert J, Duffy J, Seth J, Phillips CI, Bartholomew RS, et al. Some risk factors associated with cataract in S E Scotland: a pilot study. Trans Ophthalmol Soc UK 1982;102:331-6.

5 Sasaki H, Kojima M, Shui YB, Chen HM, Nagai K, Kasuga T, et al. The Singapore-Japan Cooperative Eye Study [abstract]. US-Japan Cooperative Cataract Research Group Meeting, Kona, HI. Kanazawa: Department of Ophthalmology, Kanazawa Medical University, 1997:66.

6 Trevithick CC, Vinson JA, Caulfield J, Rahman F, Derksen T, Bocksch L, et al. Is ethanol an important antioxidant in alcoholic beverages associated with risk reduction of cataract and atherosclerosis? Redox Report 1999;4:89-93.

7 Duthie GG, Pedersen MW, Gardner PT, Morrice PC, Jenkinson AM, McPhail DB, et al. The effect of whisky and wine consumption on total phenol content and antioxidant capacity of plasma from healthy volunteers. Eur J Clin Nutr 1998;52:733-6.

8 Rimm EB, Stampfer MJ, Ascherio A, Giovanucci E, Golditz GA, Willet WC. Vitamin E consumption and the risk of coronary disease in men. N Engl J Med 1993;328:1450-5.

9 Stampfer MJ, Hennekens CH, Manson JE, Golditz GA, Rosner B, Willett WC. Vitamin E consumption and risk of coronary disease in women. N Engl J Med 1993;328:1444-9.

10 Robertson JMcD, Donner AP, Trevithick JR. Vitamin E intake and risk of cataracts in humans. Ann NY Acad Sci 1989;570:372-82.

11 Trevithick JR, Dzialoszynski T. A new technique for enhancing luminol luminescent detection of free radicals and reactive oxygen species. Biochem Molec Biol Int 1994;33:1179-90.

12 Trevithick JR, Dzialoszynski T. Endogenous superoxide-like species and antioxidant activity in ocular tissues detected by luminol luminescence. Biochem Molec Biol Int 1997;41:695-705.

13 Spector A, Ma W, Wang RR. The aqueous humor is capable of generating and degrading $\mathrm{H}_{2} \mathrm{O}_{2}$. Invest Ophthalmol Vis Sci 1998;39:1188-97.

\section{Endpiece \\ Essential reading matter}

From the plenary session at the National Assembly for Wales, 1 December 1999. Dr Brian Gibbons (Labour, Aberavon): "Is Jane [secretary for health and social services] aware of the editorial in the $B M J$ two years ago ...?"

Jane Hutt (Labour, Vale of Glamorgan): "No, but I read it regularly now."

Submitted by John Jenkins, BMA public affairs officer, Cardiff 